\title{
Alimentação saudável: acesso à informação via mapas de navegação na internet
}

I 1 Maria Ligia Rangel-S, ${ }^{2}$ Gabriela Lamego,

${ }^{3}$ Andrea Lizabeth Costa Gomes I

Resumo: Apresentam-se e discutem-se os resultados de uma pesquisa realizada com o objetivo de desenvolver uma tecnologia de informação e comunicação via web para a promoção da alimentação saudável, mediante a facilitação do acesso à informação na internet. Buscou-se, mediante entrevistas, conhecer as concepções e identificar demandas e necessidades de informaçôes e conhecimentos sobre o tema, dentre ONGs que trabalham com saúde; e ainda, mapear informaçôes e conhecimentos acerca da alimentação saudável na web, em sítios nacionais. A partir dos resultados, elaboraram-se mapas conceituais, colocados em diálogo mediado pelos pesquisadores, com os saberes dos especialistas. Descreve-se a metodologia utilizada para construir os mapas de navegação orientados por mapas conceituais e discutem-se os desafios da gestão e do acesso à informação e ao conhecimento em saúde na internet. Destaca-se o potencial para deslocar o modelo da oferta de informação para o de construção compartilhada do conhecimento mediada por tecnologias de informação e comunicação.

> Palavras-chave: alimentação saudável; internet e saúde; tecnologia de comunicação.

\author{
${ }^{1}$ Médica; mestre em Saúde \\ Comunitária; doutora em \\ Saúde Pública; professora e \\ pesquisadora do Instituto de \\ Saúde Coletiva da Universidade \\ Federal da Bahia (ISC-UFBA). \\ Endereço eletrônico: maria. \\ lirangel@gmail.com \\ 2 Psicóloga; mestre em Saúde \\ Coletiva; doutoranda em Saúde \\ Pública do ISC-UFBA. Endereço \\ eletrônico: gabilamego@ \\ hotmail.com \\ ${ }^{3}$ Nutricionista; mestre e \\ doutora em Nutrição Humana \\ Aplicada pela Universidade \\ de São Paulo; professora \\ da Escola de Nutrição da \\ Universidade Federal da Bahia \\ (ENUFBA). Endereço eletrônico: \\ andreacgomes@gmail.com
}




\section{Introdução}

Este artigo apresenta e discute os resultados de uma pesquisa realizada com o objetivo de desenvolver uma tecnologia de informação e comunicação via web, para a promoção da alimentação saudável, mediante a facilitação do acesso à informação na internet. Buscou-se identificar demandas e necessidades de informações e conhecimentos sobre alimentação saudável das Organizações Não-Governamentais (ONG) que trabalham com saúde; mapear informações e conhecimentos acerca da alimentação saudável na web, em sítios nacionais; e construir e validar mapas de navegação que facilitem o acesso do cidadão a informações válidas, de acordo com suas necessidades, na abordagem da alimentação saudável.

O tema da alimentação saudável é sem dúvida, na sociedade atual, de grande relevância, especialmente ao se considerar a crescente tendência à obesidade no mundo inteiro e sua relação com hábitos alimentares e estilos de vida (OMS, 2004; PITANGA; LESSA, 2005). Isso tem levado governos a buscarem medidas para fazerem frente aos riscos à saúde que se sobrepõem (WHO, 1998; 2003).

Alimentação, nutrição e a prática regular de atividade física são referidas como componentes de um modo de viver saudável, circunscrevendo-se na atualidade entre os determinantes e condicionantes da saúde, e ocupam lugar de destaque na agenda da saúde no mundo todo, em especial nas políticas de Promoção da Saúde (OMS, 2004; BRASIL, 2006).

Entretanto, na atualidade, a situação alimentar, nutricional e de atividade física da população, no âmbito nacional ou mundial, caracteriza-se por uma alimentação não saudável, pois se tem demonstrado o consumo excessivo de alimentos com alto teor de gorduras e carboidratos simples, e baixa quantidade de fibras, o que associado à falta ou insuficiência de atividade física, é em grande parte responsável pelo excesso de peso, aumentando os fatores de riscos (que coexistem e interagem) para as doenças crônicas não-transmissíveis - DCNT (WHO, 2003; OMS, 2004). Esse cenário desfavorável, considerado de emergência, motivou recentemente organizações internacionais e nacionais a incluírem a temática de forma estratégica na agenda de saúde (OMS, 2004; BRASIL, 2006). Assim, a Organização Mundial da Saúde (OMS) apresentou a Estratégia Global (EG) para Alimentação, Atividade Física e Saúde em 2004, e o Ministério da Saúde (MS) do Brasil lançou o Guia Alimentar para a População Brasileira, em 2005, 
como uma ferramenta da Política Nacional de Alimentação e Nutrição (PNAN).

Posteriormente, com o propósito de articular estes documentos, em 2006, o MS do Brasil instituiu a Política Nacional de Promoção da Saúde (BRASIL, 2003, 2005, 2006). Com isto destacam-se o vigor e a visibilidade que a temática da promoção da alimentação saudável ocupa na agenda nacional de saúde pública.

Desenvolve-se na sociedade a busca frequente na internet de informações sobre saúde em geral e sobre alimentação e nutrição em particular. Em 2003, segundo Soares (2004), foram encontradas 29.200 ocorrências da palavra "saúde" no título de sítios, o que indicava a rapidez com que o tema se expandiu na rede. O autor destaca que em 1998 foi realizado estudo do Cyber-Dialogue/Internet Health Day, que revelou que um terço dos usuários buscaram informações sobre dieta e nutrição.

Em alguns países, a utilização da internet como ferramenta de educação nutricional começou a ser utilizada nos anos 1990, mostrando-se promissora frente às intervençôes convencionais, principalmente no que se refere aos hábitos alimentares, podendo se aproximar ao aconselhamento alimentar individualizado (BRUG et al., 2003; PAINTER, 2000; HOLLER, 2000). Um estudo realizado entre holandeses, considerando os hábitos alimentares, foi conduzido a fim de avaliar o impacto imediato da intervenção nutricional via web em relação à orientação tradicional, e mostrou que a Word Wide Web é uma via que pode ser utilizada para o fim de uma intervenção personalizada e mais efetiva (OENEMA et al., 2000).

Um estudo realizado por Gomes et al. (2005) com 415 participantes, com o objetivo de desenvolver um instrumento via correio eletrônico para orientar e motivar práticas alimentares saudáveis, concluiu que a internet, por sua agilidade e baixo custo, pode ser utilizada para promover intervençóes nutricionais, de forma interativa ou coadjuvante, sem exigir locomoção e demanda de tempo do participante. Diferentes autores defendem a importância de que sejam estudadas formas para orientar melhor as escolhas alimentares da população e a aquisição de hábitos alimentares saudáveis, contribuindo para a promoção da saúde (GOMES et al., 2005; GALANTE; COLLI, 2003). Contudo, reconhecese que a educação alimentar e nutricional contém elementos complexos e até conflituosos, que justificam esforços para a busca de consenso sobre conteúdos, métodos e técnicas do processo educativo, considerando os diferentes espaços 
geográficos, econômicos e culturais (BRASIL, 2003). Informaçōes sobre alimentos, se saudáveis ou perigosos, se misturam na internet, tornando difícil selecionar o confiável do não confiável, o bom do ruim.

Mas o uso da internet para o acesso à informação em saúde é crescente na sociedade contemporânea, seja em domicílio ou no trabalho, já fazendo parte do cotidiano de grande parte da população, facilitando a circulação e troca de informaçôes em todo o mundo. $\mathrm{O}$ crescimento exponencial das possibilidades de acesso a dados e informaçôes verificado após o desenvolvimento das tecnologias da informação, com o advento da comunicação mediada por computadores (CMC), o aumento da capacidade interativa, o aprimoramento dos recursos de multimídia, aliados ao significativo crescimento da Internet, já são fatos bastante discutidos por diversos autores (CASTELLS, 1999; MELO, 2003; AGUIAR, 1997).

O entanto, a ampliação e a diversificação deste espaço de construção do conhecimento, no qual uma parcela considerável do conteúdo surge de maneira espontânea, aleatória e com propósitos e finalidades bastante diversos, trazem consigo aspectos fundamentais a serem ressaltados, que se referem à qualidade e confiabilidade dessas informaçōes (CASTIEL, 2006). Isto porque todo usuário que possua computador conectado à rede, e disponha de um software apropriado, pode inserir conteúdos na Internet. Segundo Okada (2004), diante da quantidade de informações disponíveis, é impossível sua assimilação, e até indesejável, tornando-se o objetivo do aprendizado não o domínio de um assunto, detendose todas as informações, mas saber onde e como encontrá-las.

Frente a essas questões, através de pesquisa desenvolveu-se uma tecnologia, mediante a experimentação do uso de softwares de cartografia cognitiva (Cmap Tools e Nestor Web Cartographer), para o mapeamento de informações em saúde, combinando a pesquisa sobre noções e conceitos circulantes acerca da alimentação saudável, entre profissionais que atuam com temas de saúde, especialistas e não-especialistas em nutrição, com o objetivo de construir mapas virtuais de navegação, facilitadores do acesso da população a uma informação selecionada sobre alimentação saudável.

\section{Mapas de conhecimento e navegação}

A construção dos mapas se fundamenta no estudo de duas principais questões: de um lado, trata-se de compreender o ciberespaço e, de outro, apreender as principais 
noções e conceitos circulantes sobre alimentação saudável, reconhecendo-a como uma noção polissêmica e mesmo polêmica.

Para aproximar-se ao ciberespaço, o estudo se fundamenta em teorias que compreendem o espaço virtual como um lugar ampliado de interação social, em que ocorrem processos de aprendizagem autogeridos, móveis e contextuais das competências, em meio ao generalizado intercâmbio de saberes (LEVY, 2003).

As páginas Web exprimem ideias, desejos, saberes, ofertas de transação de pessoas e grupos humanos. Por trás do grande hipertexto fervilham a multiplicidade e suas relações. No ciberespaço, o saber não pode mais ser concebido como algo abstrato ou transcendente. Ele se torna ainda mais visível - e mesmo tangível em tempo real - por exprimir uma população. As páginas da Web não apenas são assinadas como as páginas de papel, mas frequentemente desembocam em uma comunicação direta, por correio digital, fórum eletrônico ou outras formas de comunicação por mundos virtuais como os MUDs ou os MOOs ${ }^{1}$. Assim, contrariamente ao que nos leva a crer a vulgata midiática sobre a pretensa "frieza" do ciberespaço, as redes digitais interativas são fatores potentes de personalização ou de encarnação do conhecimento (LEVY, 1999, p.162).

Dentre os desafios apontados por Levy (1999), face ao ciberespaço, destaca-se a necessidade de preparo para atuar nele, considerando-se algumas características da sociedade atual, tais como: a maioria dos saberes adquiridos torna-se rapidamente obsoleta; a acelerada temporalidade social que cursa com as desordens da economia; e o ritmo precipitado das evoluções científicas e técnicas. Assim, indivíduos e os grupos se deparam com um "saber-fluxo caótico", de curso pouco previsível e não mais com saberes estáveis. Impossível tentar conter e organizar esse saber-fluxo, mas talvez possível aprender a navegar. Para o autor, a despeito do caos informacional gerado, esta é uma situação favorável à democratização do saber, uma vez que possibilita uma relação intensa com o aprendizado, com a transmissão e a produção de conhecimentos não mais reservados a uma elite.

Nesse quadro, um dos papéis do poder público seria o de permitir a todos o acesso aberto e gratuito a midiatecas, centros de orientação, documentação e autoformação, a pontos de entrada no ciberespaço, sem negligenciar a indispensável mediação humana do acesso ao conhecimento; e regular e animar uma nova economia do conhecimento, na qual cada indivíduo, cada grupo, cada organização sejam considerados como recursos potenciais de aprendizado a serviço de percursos de formação contínuos e personalizados (LEVY, 2003). Além disso, questões relativas à qualidade e confiabilidade das informaçôes sobre 
saúde que circulam na internet são pertinentes a este estudo. Segundo Lopes, diante do caos informacional na internet,

$\mathrm{Na}$ área de saúde, existe um consenso internacional sobre a questão da qualidade da informação por parte de instituições governamentais, não-governamentais, associaçôes de classe, profissionais de saúde e profissionais das mais diversas áreas afins, como atestam os estudos e critérios de qualidade de inúmeras instituições [...] (LOPES, 2004, p. 84).

Soares (2004) discute estudo conduzido por Aspden e Katz, em 1997, com 800 usuários de Internet, nos Estados Unidos, que evidenciou o valor que os entrevistados creditam à informação que circula na Internet, com apenas um terço mostrando-se cautelosos e 5\% considerando-a sem credibilidade. A leitura crítica foi encontrada em 20\%, que afirmaram terem lido informação irresponsável; 27\% enganosa e 31\% muito comerciais. Segundo Soares,

[...] numa escala de ceticismo, construída pelos autores a partir das respostas, os mais céticos apresentavam maior grau de instrução e maiores habilidades de Internet. Os mais céticos eram também os que mais frequentemente acessaram informações de saúde e os mais prováveis de discutir essas informações com outras pessoas (SOARES, 2004, p.3).

Castiel e Vasconcelos-Silva (2003) também argumentam sobre a qualidade da informação em saúde na rede, afirmando, mediante a leitura de vários autores, que é considerável o problema de controle de qualidade dos conteúdos relativos à saúde na Internet. Ressaltam que, em geral, "há informações contraditórias e/ ou datadas e/ou incompletas em diversos aspectos de seus temas específicos" (CASTIEL; VASCONCELOS-SILVA, 2003, p. 56). Segundo os autores,

Em termos globais, as preocupaçōes quanto à qualidade da informação estão voltadas para: educar o consumidor, estimular a regulação dos emissores de informação em saúde, possuir instâncias não comprometidas para avaliar a informação e estabelecer sanções em casos de disseminação nociva ou fraudulenta de informação (CASTIEL; VASCONCELOS-SILVA, 2003, p. 56).

Cabe ainda considerar a importância da internet na divulgação do conhecimento científico, haja vista a crescente publicação de revistas científicas online e a observação de Castro de que

Nas últimas décadas do século XX, a Internet alterou não apenas a dinâmica do fluxo da comunicação científica, mas também o modo de fazer ciência, com a integração da comunidade científica com outros setores da sociedade, atuando em redes transdisciplinares e heterogêneas de colaboração entre instituições de natureza variada (CASTRO, 2006, p. 59). 
Desse modo, iniciativas de aproximar o conhecimento científico aos cidadãos comuns devem facilitar o acesso à informação. Neste estudo, trata-se de mapeá-las, traçar rotas, selecionar e articular o que é relevante, para oferecer o que se assume como informações válidas, isto é, aquelas do interesse do público, selecionadas e articuladas conceitualmente em diálogos profícuos com estudiosos do assunto e setores sociais interessados, permitindo a aproximação entre os saberes científicos/ acadêmicos e outros saberes circulantes do público. Assim, em um cenário onde a geração, transmissão e distribuição de informações ocorrem livremente e com atualização constante, cumpre questionar: quais as que realmente interessam para a proteção e promoção da saúde? Onde encontrá-las de maneira rápida e eficiente? Como assegurar sua qualidade e confiabilidade?

Nesse sentido, no âmbito de um projeto de desenvolvimento tecnológico para a gestão do conhecimento em saúde, desenhou-se um espaço com o objetivo de disponibilizar mapas de navegação para facilitar o acesso à informação em Saúde Coletiva disponível na rede, a partir da identificação das necessidades dos diversos atores sociais, objetivando a construção do conhecimento, em caráter permanente, de forma interativa, democrática e descentralizada. Assim, não se pretende limitar as possibilidades de uso à simples consultas ou transmissão de informações, mas sim, facilitar a navegação e construção de caminhos multirreferenciais e multidirecionais de informação, ensejando viabilizar a valorização e o fortalecimento da participação social e da democratização dos saberes e conhecimentos em saúde.

Embora considerando a carga semântica do termo "alimentação saudável", em torno do qual não há consenso (SILVA, 2002), neste estudo admite-se, a partir do que está posto na Estratégia Global, na PNAN, no Guia Alimentar, que a alimentação saudável se refere à melhor prática alimentar atribuída pelos sujeitos, capaz de contribuir para prevenir o avanço das doenças crônicas (OMS, 2004; BRASIL, 2003, 2005, 2006).

\section{Abordagem teórico-metodológica}

Visando à consecução dos objetivos deste estudo, buscou-se identificar estratégias, técnicas e ferramentas que pudessem auxiliar a busca, seleção, análise crítica e elaboração dos mapas de navegação. Nesse sentido, a cartografia cognitiva, potencializada pelo uso de softwares, apresentou-se como dispositivo 
privilegiado. Trata-se de um recurso metodológico de mapeamento que utiliza a elaboração de mapas que se aproximem das características funcionais e estruturais da representação, significação e construção de conhecimento, favorecendo o processo de aprendizagem.

Segundo Okada (2002), os mapas não são artefatos neutros, pois são produzidos em um processo criativo e de construção do conhecimento, e expressam decisões sobre o que incluir e excluir e o que querem comunicar. Assim,

Mapas bem desenhados são uma efetiva fonte de comunicação porque eles exploram as habilidades da mente para ver relações em suas estruturas físicas, permitem compreensão das complexidades do ambiente, reduz o tempo de procura e revela relações especiais que de outra forma não seriam notadas (DODGE; KITCHEN, 2001 apud OKADA, 2002, p. 3).

Assim, o conceito de mapeamento deixa de ser utilizado apenas como instrumento de referência geográfica, ampliando suas possibilidades enquanto dispositivo facilitador do entendimento dos processos cognitivos. Dentre as diversas técnicas de mapeamento propostas - tais como mapas conceituais, mapas virtuais, mapas da mente, mapas do pensamento e mapas de imagens -, foram selecionadas como recurso da de gestão do conhecimento e da informação em Saúde Coletiva as duas primeiras, devido à maior afinidade com a missão do sítio.

Os mapas conceituais, idealizados por Novak em 1970, fundamentam-se em uma teoria construtivista, a Psicologia Cognitiva de Ausubel, preconizando o estabelecimento de relações, interpretações e conexões entre diferentes conceitos de maneira esquemática (representações gráficas semelhantes a diagramas). Tomam como ponto de partida os conceitos mais gerais, indo até os mais específicos, de forma ordenada e hierarquizada. Desse modo, favorecem o entendimento do caminho percorrido na construção do conhecimento. Já os mapas virtuais ajudam a visualizar e compreender os novos cenários digitais, nas linhas das redes de comunicação global e das variadas fontes de informação online (DODGE; KITCHEN, 2001 apud OKADA, 2003).

Os mapas conceituais foram construídos neste estudo utilizando-se o software Cmap Tools ${ }^{2}$ e os mapas virtuais mediante o software Nestor Web Cartographer ${ }^{3}$, ambos de acesso gratuito. Os primeiros serviram de "rotas de navegação" para a pesquisa na internet e construção dos segundos, que conduziram aos sítios de interesse. O Nestor é uma ferramenta útil ao registro da navegação e seleção de sítios de interesse. 
O Nestor permite registrar o caminho de navegação na Internet através de mapas (pontos e setas que indicam respectivamente endereços de sites e a sequência de navegação). Este software, além de possibilitar a organização de endereços de sites significativos (apagar, mover, relacionar, agrupar), possui uma série de recursos para trabalhar com o conteúdo das páginas web (selecionar informaçôes, destacá-las, reagrupá-las num novo texto, localizar palavras-chave, construir novos sites). Mais do que um cartógrafo da Internet é também um software para o aprendizado colaborativo (OKADA, 2003, p. 11).

Assim, a escolha deste browser é justificada, na medida em que permite registrar o caminho percorrido pelo usuário por meio de mapas, oferecendo vários recursos para organização das informações, utilizando uma interface amigável, permitindo a organização de verdadeiras bibliotecas iconográficas (OKADA, 2003a).

Para a construção do mapa de alimentação saudável, partiu-se da pesquisa das noções e conceitos e das demandas e necessidades de informações e conhecimentos sobre o tema, mediante a interação com profissionais que atuam em ONGs que trabalham com saúde, no Brasil, identificadas no sítio da Associação Brasileira de Organizaçōes Não-Governamentais (ABONG). Esta foi criada em 1991, como forma de representar coletivamente as ONGS junto ao Estado e aos demais atores da sociedade civil. Declara, em seu sítio, como seu principal objetivo, "representar e promover o intercâmbio entre as ONGS empenhadas no fortalecimento da cidadania, na conquista e expansão dos direitos sociais e da democracia”. No período da pesquisa, a ABONG contava com 270 associadas que declaravam atuar na esfera pública em áreas como direitos humanos, políticas públicas, questôes agrárias e agrícolas, questôes urbanas, desenvolvimento regional, meio ambiente e ecologia. ${ }^{4}$

Foram inicialmente identificadas 72 ONGS de diferentes regiōes do país, que atuam na área temática da saúde, das quais 58 foram elegíveis após o refinamento da pesquisa, quando foram excluídos os sítios desatualizados. Destas, sete se recusaram a participar e outras 18 não responderam à sensibilização realizada pelos pesquisadores, totalizando 33 participantes do estudo.

A pesquisa se deu mediante entrevistas gravadas via telefone e eletrônica, através do sítio do projeto em que se deu a pesquisa, as quais foram transcritas e analisadas. O informante-chave tomou conhecimento do termo de consentimento livre e esclarecido, apresentado e aceito por via eletrônica, ou audiogravação, no momento da entrevista telefônica. 
Para a produção de dados, foi elaborado um formulário contemplando três blocos de questôes: 1) identificação (da ONG e do responsável pelo preenchimento do formulário); 2) saúde e nutrição (principais problemas de saúde dos públicos atendidos, atividades realizadas na área de alimentação e nutrição, percepções sobre saúde e alimentação saudável); 3) nutrição e informação (demandas de informação sobre alimentação e nutrição, temas de interesse sobre alimentação saudável e principais meios de comunicação utilizados para obter informaçóes alimentação e nutrição).

Os resultados foram sistematizados e analisados, servindo de subsídio para a realização de três oficinas de elaboração de mapas conceituais junto a especialistas da Escola de Nutrição da Universidade onde se desenvolveu o estudo, como forma de diálogo dos saberes das ONGs e os dos profissionais, mediado pelas pesquisadoras. Um mapa conceitual sobre alimentação saudável foi elaborado a partir dos resultados das entrevistas com as ONGs, e foi discutido nas oficinas, agregando-se os diferentes conceitos acerca do tema.

As oficinas contaram com a participação de nutricionistas especializadas nas áreas de clínica, planificação e gestão de serviços de saúde, epidemiologia e ciências sociais em saúde. Foram envolvidas 11 nutricionistas, incluindo docentes e alunos da pós-graduação, com formação e atuação nas áreas de clínica, planificação e gestão de serviços de saúde, epidemiologia e ciências sociais em saúde. Foi posto em discussão o mapa conceitual sobre Alimentação Saudável elaborado pelas pesquisadoras, a partir dos resultados das entrevistas com as ONGs. As discussões sobre as noções contidas neste primeiro mapa, entre as especialistas, permitiram colocar em evidência a diversidade das concepçôes em interação acerca da alimentação saudável, desde os saberes da clínica, em diálogo com os da epidemiologia e das ciências sociais. Da primeira oficina, surgiram elementos que levaram à reelaboração do mapa preliminar, resguardando-se o que foi demandado pelas ONGs, mas buscando articular marcos conceituais sobre cura, prevenção e promoção, mesmo assumindo-se as especificidades epistemológicas envolvidas e as subjetividades implicadas. As participantes se envolveram também na elaboração do mapa de um subtema que lhes fosse mais familiar, mediante o uso do Cmap. Todas as interessadas foram treinadas no manejo dos softwares Cmap e Nestor. Foi então realizada a busca de sítios na internet, orientada por um protocolo com palavras-chave definidas pelas autoras 
dos mapas, e mediante o uso do Nestor. Todos os mapas voltaram a ser discutidos

com as formuladoras em oficinas subsequentes e foram articulados entre si, conformando um novo mapa. Este foi submetido a críticas do grupo, enquanto as buscas foram minuciosamente analisadas quanto à coerência temática e aos critérios definidos para realizá-la.

Os procedimentos de busca da informação na internet seguiram um protocolo de uso do software Nestor 2006, navegando-se no Google, utilizando-se as seguintes palavras-chave: "segurança alimentar", "alimentação e prevenção de doenças", "aproveitamento de alimentos", "higiene de alimentos", "corpo e alimentação", "ciclo de vida e alimentação", "alimentos regionais", "prazer em comer”. Outras palavras-chave poderiam ser utilizadas, se necessário, informando-se sempre o respectivo número de ocorrências. As datas do início e fim da pesquisa do tema na rede eram observadas e registradas, constando o número de ocorrência em cada momento, assim como o tempo gasto total/tema.

A seleção dos sítios encontrados obedeceu aos seguintes critérios: a polifonia das fontes de informação, considerando-se: a) a inclusão das vozes oficiais - Ministério da Saúde, OPAS, secretarias estaduais e municipais de saúde; universidades públicas, federais, estaduais e municipais-; b) vozes da ciência publicações científicas; e vozes de organizações da sociedade civil, que contassem com informações confiáveis sobre o tema, validadas por especialistas; c) vozes de produtos culturais diversos, excluindo-se sítios comerciais. Assim, foram selecionados vários tipos de produtos e formatos nos sítios, tais como textos documentais, artigos científicos, normas, leis, aulas em Powerpoint, entrevistas, resumos de livro, outros em formatos de textos, vídeos, filmes, livros, endereços de bibliotecas e videotecas virtuais e outros que pudessem contribuir para reflexões e debates sobre alimentação saudável em suas múltiplas dimensões.

Em todas as pesquisas realizadas selecionou-se previamente, na ferramenta de pesquisa, exclusivamente "páginas do Brasil", em virtude da especificidade do público, obedecendo ao roteiro estabelecido a partir dos mapas conceituais, elaborados pelos pesquisadores.

Uma vez elaborados os mapas conceituais, estes foram submetidos à apreciação das 33 ONGs convidadas a visitar o sítio e preencher um formulário de avaliação, ou a responderem as entrevistas telefônicas. Novamente nesta etapa foi necessário o contato telefônico, uma vez que poucas ONGs responderam 
positivamente ao convite de preenchimento do formulário on-line. Assim, foram realizados todos os esforços para que elas conhecessem e avaliassem o produto tecnológico. Do total de 33 ONGs que participaram da pesquisa, nove responderam ao formulário eletrônico disponibilizado e as demais 24 foram entrevistadas via telefone na função viva-voz. $\mathrm{O}$ material gerado pelas entrevistas telefônicas foi gravado e posteriormente transcrito para ser analisado juntamente com as respostas obtidas nos formulários.

\section{Resultados}

\section{Caracterização das ONGs: áreas de atuação e ações realizadas}

As ONGs que participaram do estudo atuavam no âmbito municipal $(36,4 \%)$ e estadual (27,3\%), desenvolvendo ações educativas direcionadas sobretudo ao público adolescente $(48,5 \%)$, adulto $(45,5 \%)$, mulheres $(42,4 \%)$ e crianças $(39,4 \%)$, além de atuarem na área da saúde. Estas identificaram como principais problemas e necessidades de saúde da população atendida: doenças crônicas (66,6\%); DST/Aids $(42,4 \%)$ e doenças carenciais (desnutrição, anemia e raquitismo) $42,4 \%$ (quadro 1 ).

Quadro 1. Características das ONGs quanto à área de atuação, público e problemas e necessidades de saúde da população atendida

\begin{tabular}{|l|c|}
\hline Área de atuação & $36,4 \%$ \\
\hline Municipal & $27,3 \%$ \\
\hline Estadual & $48,5 \%$ \\
\hline Público destinatário & $45,5 \%$ \\
\hline Adolescentes & $42,4 \%$ \\
\hline Adulto & $39,4 \%$ \\
\hline Mulheres & \\
\hline Crianças & $66,6 \%$ \\
\hline Principais problemas e necessidades de saúde da população atendida & $42,4 \%$ \\
\hline Doenças crônicas & $42,4 \%$ \\
\hline DST/AIDS & \\
\hline Doenças carenciais (desnutrição, anemia e raquitismo) & \\
\hline
\end{tabular}


As ONGs declararam realizar ações educativas $(69,9 \%)$ e preventivas (57,6\%), de promoção da saúde (30,3\%), assistenciais (15\%) e de controle social e fortalecimento de políticas públicas (9\%). Aproximadamente 55,0\% das ONGs declararam realizar trabalhos sobre alimentação e nutrição, sendo que em $61,1 \%$ tratava-se de orientação alimentar; em $44,4 \%$ de ofertas de refeições e em $44,4 \% \%$ de práticas educativas. A falta de informação apareceu como a segunda dificuldade para ter uma alimentação saudável $(63,6 \%)$, atrás da dificuldade financeira $(66,6 \%)$, segundo o quadro 2 .

Quadro 2. Características das ONGs quanto ao tipo de ação em saúde e alimentação

\begin{tabular}{|c|c|}
\hline \multicolumn{2}{|l|}{ Tipos de ação } \\
\hline Educativa & $69,9 \%$ \\
\hline Preventiva & $57,6 \%$ \\
\hline Promoção da saúde & $30,3 \%$ \\
\hline Ações assistenciais & $15 \%$ \\
\hline Controle social e fortalecimento de políticas públicas & $9 \%$ \\
\hline \multicolumn{2}{|l|}{ Trabalhos de alimentação e nutrição } \\
\hline Orientação alimentar & $61,1 \%$ \\
\hline Ofertas de refeição & $44,4 \% \%$ \\
\hline Práticas educativas & $44,4 \%$ \\
\hline \multicolumn{2}{|l|}{ Dificuldades para ter uma alimentação saudável } \\
\hline Financeira & $66,6 \%$ \\
\hline Falta de informação & $63,6 \%$ \\
\hline
\end{tabular}

\section{Concepções sobre alimentação saudável}

As concepções de alimentação saudável relacionaram-se às noções de: variedade; equilíbrio; quantidade de refeições; segurança alimentar; fonte de prazer e respeito ao hábito alimentar, restringindo-se ou moderando-se o consumo de gorduras e açúcares; direito ao acesso a alimentos em qualidade e quantidade suficientes. Ressaltaram-se dificuldades para ter alimentação saudável relacionadas à condição 
econômica, informação e conhecimento, e ritmo de vida. Os/as entrevistados/as apontaram como dicas para se obter uma alimentação saudável o conhecimento do corpo nas diferentes fases da vida e das especificidades dos alimentos adequados a cada fase e a prática de comer associado ao prazer e a bons sentimentos.

Como temas destacados para a busca de informação, apareceram: alimentação nas diferentes fases da vida; aproveitamento alimentar; higiene dos alimentos. As principais demandas por informação foram: alimentação saudável, considerando disponibilidade e acessibilidade; necessidades orgânicas de alimentação; prevenção de doenças e propriedades curativas dos alimentos; reeducação alimentar.

$\mathrm{Na}$ apresentação e discussão do mapa conceitual dos participantes da ONGs aos especialistas, foram identificadas lacunas de duas ordens: a primeira, referente a questôes econômicas e políticas relacionadas à alimentação e nutrição, tais como: a) segurança alimentar, relacionada a soberania alimentar, direitos humanos, consumo de alimentos, disponibilidade e abastecimento, alimentos seguros; b) alimentação e sociedade, considerando aspectos históricos, políticos e culturais; c) promoção da saúde, envolvendo alimentação equilibrada, alimentos funcionais e atividade física. Este último ponto foi o mais polêmico, revelando a dificuldade de definir promoção da saúde e alimentação saudável.

A experiência de confrontar saberes das ONGs e de especialistas em saúde e nutrição da academia mostrou, como ponto comum, forte influência do saber biomédico, que dificulta a separação entre promoção e prevenção, levando, de um lado, à formulação de demandas para o poder curativo dos alimentos e, de outro, à persistência da doença no foco do debate sobre a promoção da saúde.

Enquanto as demandas por informação das ONGs se mostraram fortemente marcadas pela hegemonia do modelo biomédico (normativas, prescritivas e voltadas para doenças), esta esteve presente também no discurso dos especialistas que apontavam para as funcionalidades dos alimentos.

\section{Mapa Conceitual e de Navegação}

O mapa conceitual sobre alimentação saudável se expressa graficamente na figura 1, articulando as noções dos participantes das ONGs e dos especialistas sobre o tema. Essa figura representa também o mapa final, conceitual e de navegação, disponível, como produto tecnológico disponibilizado no endereço eletrônico da universidade 5 . 


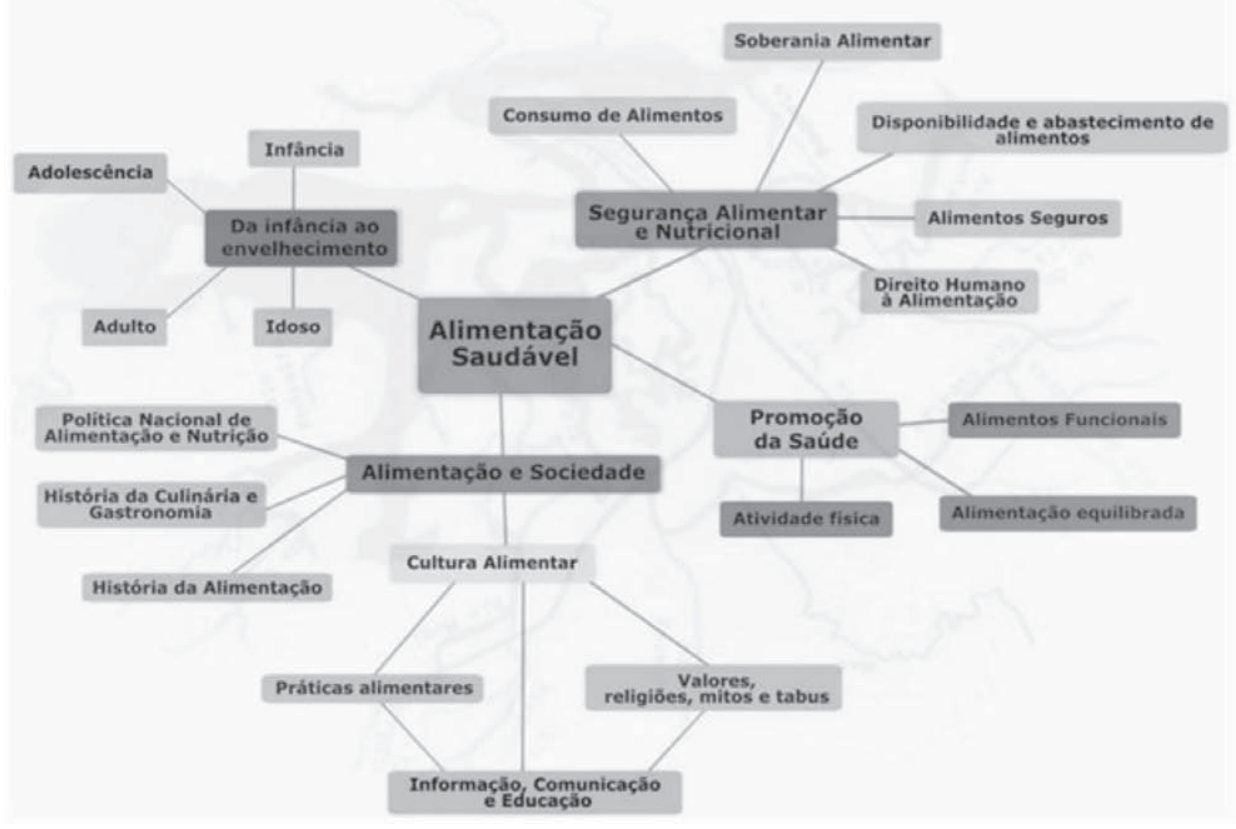

A figura 2 exemplifica a iconografia da busca realizada mediante o software Nestor Web Cartographer para a construção do mapa de navegação, orientado pelos mapas conceituais sobre Alimentação Saudável. Os sítios selecionados foram classificados segundo os conceitos-chave que deram origem a quatro mapas interconectados com as seguintes temáticas: "Alimentação e Sociedade", que articula história da alimentação, história da culinária e gastronomia, política nacional de alimentação e nutrição; e cultura alimentar, subdividido em práticas alimentares, valores, religiōes, mitos e tabus; e informação, comunicação e educação; "Promoção da Saúde", conectando alimentos funcionais; atividade física e saúde; alimentação e saúde; "Segurança Alimentar e Nutricional", que vincula consumo de alimentos; soberania alimentar; direito humano à alimentação; alimentos seguros; e disponibilidade e abastecimento de alimentos; e "Da Infância ao Envelhecimento", que contempla as distintas fases da vida: infância; adolescência; adultos; e idoso. 
Figura 2. Iconografia dos sítios identificados e classificados mediante o uso do Nestor Web Cartographer

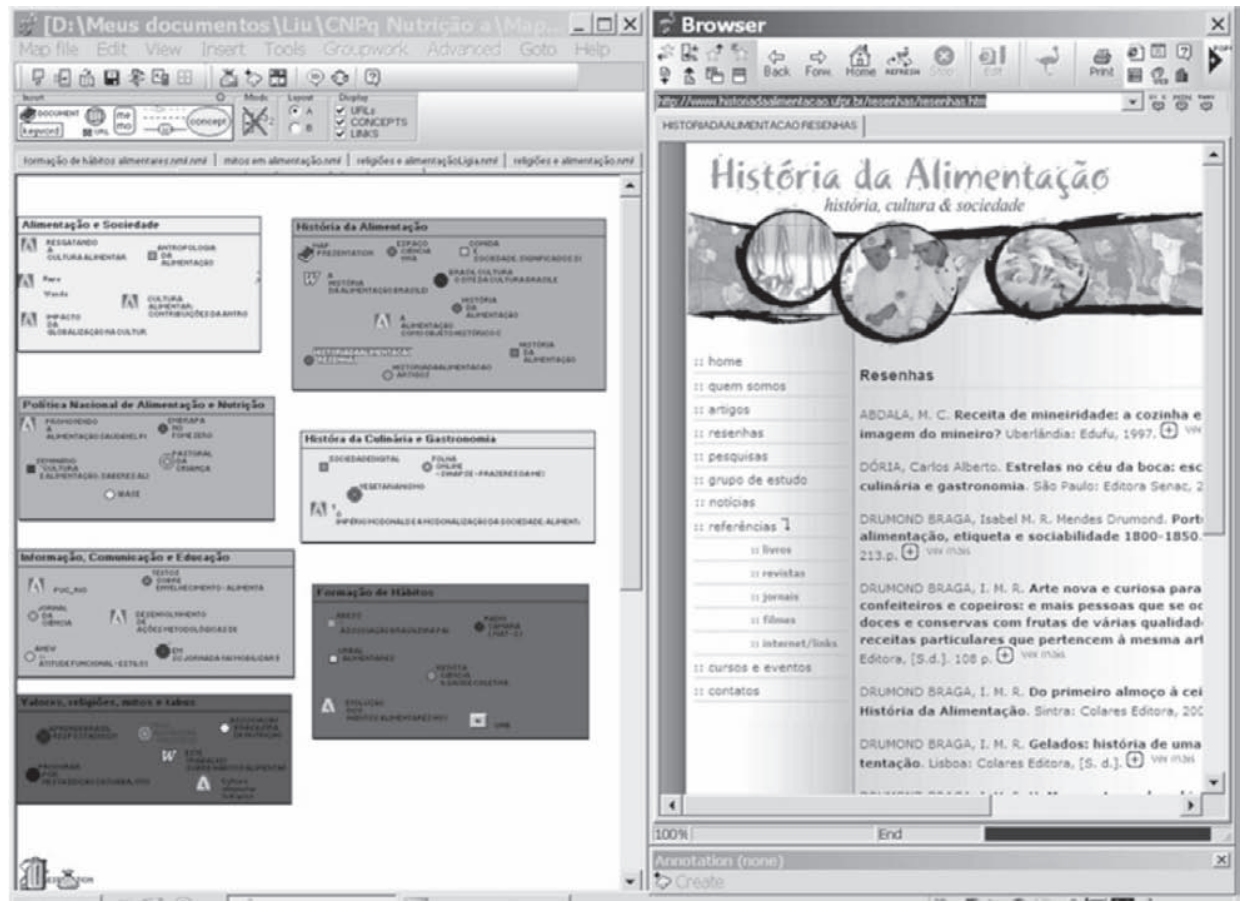

Os mapas publicados no sítio do projeto direcionam o usuário para sítios contendo informações e conhecimentos que podem responder às demandas e necessidades do grupo social focalizado pela pesquisa e seus usuários.

\section{Consideraçõos Finais}

Os mapas produzidos foram originados de um processo de construção de conhecimento de caráter dialógico, entre profissionais que realizam ações de saúde em ONGs no Brasil e especialistas em saúde e nutrição, mediado pelas pesquisadoras - portanto, um conceito construído de modo compartilhado para a produção de uma tecnologia de gestão da informação orientada como construção de sentido. Isto é, "criada pelos observadores dos quais nunca pode ser separada. [...] a comunicação da informação é concebida como diálogo entre parceiros semelhantes, afastando-se da proposta de transmissão da informação de um polo emissor a um receptor", como propõe Soares (2004, p. 13). A inclusão do público 
na criação do produto, além de enriquecê-lo, aproxima-o da realidade dos usuários que podem nele reconhecer-se, e agregar aos seus, novos conhecimentos.

A seleção de sítios vinculados a conceitos buscou obedecer aos critérios de credibilidade e de confiabilidade da informação, a partir da seleção criteriosa das fontes, como já se vem observando em diversos organismos internacionais. Contudo, há que se ressaltar a disputa simbólica no campo da saúde, em que saberes biomédicos são hegemônicos, em detrimento dos que apontam para a proteção e promoção da saúde, tomando-se esta em seu conceito ampliado. Notase, assim, a recorrência de busca de sítios sobre alimentação na prevenção de doenças e de riscos alimentares.

No entanto, mostra-se o potencial para se estabelecerem fluxos de comunicação e navegação em ambientes multirreferenciais e multidirecionais de informação, aberto à participação e ao diálogo, que sugere aos internautas outras possibilidades de acesso a informações, como parte agregada à rede semântica em que inscreve sua noção de alimentação saudável.

A construção de um mapa conceitual pode ainda contribuir para abordar o tema da alimentação saudável em sua complexidade, afastando-se da visão puramente biomédica, uma vez que não se propõe a abordar normativas, prescrições e tampouco se voltar para doenças. Isso significou um exercício de repensar os discursos dos especialistas, para operacionalizar o conceito ampliado de alimentação saudável e promoção da saúde, no nível da informação. Ademais, os mapas de navegação elaborados são recursos adicionais aos processos de aprendizagem colaborativa, via web, uma vez que são expressões conceituais que representam demandas e necessidades de informações do público pesquisado.

Além disso, os mapas poderão ser utilizados como suporte didático a atividades de ensino sobre nutrição e saúde, junto a professores de escolas de ensino fundamental e médio, e outros públicos, inclusive os trabalhadores da saúde. Neste sentido, os mapas podem contribuir para a redução de assimetrias entre profissionais e usuários no acesso à informação rápida e com certo grau de segurança sobre nutrição, alimentação e saúde, na internet, aproximando os saberes científicos daqueles que circulam nas redes sociais de comunicação do público leigo.

Por fim, ressalta-se que a metodologia de construção de mapas conceituais baseada na pesquisa de concepção, demandas e necessidades e na aproximação dos diferentes saberes em torno da alimentação saudável, expressa nos mapas 
conceituais elaborados, mostrou potencial para deslocar o modelo da oferta de informação para o de construção compartilhada do conhecimento mediada por tecnologias de informação e comunicação.

Necessidades e expectativas futuras dos diferentes públicos devem alimentar e atualizar os mapas, que requerem tecnologia flexível, capaz de remodelar os mapas de acordo com as mudanças ocorridas nos processos de circulação da informação na sociedade e no ciberespaço, de modo que assuntos, anotações e novos roteiros sugeridos pelos usuários possam ser acrescentados, mediante a interação do portal com os usuários, através do preenchimento e envio de formulário eletrônico de avaliação disponibilizado na página web, contribuindo para a ampliação da rede de conhecimentos dos usuários. ${ }^{6}$

\section{Referências}

AGUIAR S. Desatando os nós da rede. Rio de janeiro: Senac Nacional, 1997.

BRASIL. Ministério da Saúde. Secretaria de Atenção à Saúde. Política Nacional de Promoção da Saúde. Brasília, DF, 2006 (Série B. Textos Básicos em Saúde).

BRASIL. Ministério da Saúde. Secretaria de Atenção à Saúde. Coordenação Geral da Política de Alimentação e Nutrição. Guia Alimentar para a população brasileira: promovendo a alimentação saudável. Brasília, DF, 2005 (Série A. Normas e Manuais Técnicos).

BRASIL. Ministério da Saúde. Secretaria de Atenção à Saúde. Departamento de Atenção Básica. Política Nacional de Alimentação e Nutrição. 2 ed. rev. Brasília, 2003.

BRUG, J.; OENEMA, A.; CAMPBELL, M. Past, present, and future of computer-tailored nutrition education. Am J Nutr, v. 77, supl, p. 1038-1034, 2003.

CASTELLS, M. A Era da Informação: economia, sociedade e cultura, v.1. São Paulo: Paz e Terra, 1999.

CASTIEL, L.R. VASCONCELOS-SILVA, P.R. Precariedades do excesso: informação e comunicação em Saúde Coletiva. Rio de Janeiro: Fiocruz, 2006.

CASTIEL, L.D.; VASCONCELLOS-SILVA, P.R. A interface Internet/S@úde: perspectivas e Desafios. Interface - Comunic, Saúde, Educ, v7, n13, p.47-64, ago 2003. Disponível em http://www.scielo.br/pdf/icse/v7n13/v7n13a03.pdf Acesso em: 20 set 2011.

CASTRO, R.CF. Impacto da Internet no fluxo da comunicação científica em saúde. Rev Saúde Pública, v. 40, N Esp, p. 57-63, 2006. Disponível em http://www.scielosp.org/pdf/ rsp/v40nspe/30623.pdf Acesso em: 20 set 2011.

GALANTE A.P; COLLI, C. A utilização da World Wide Web como ferramenta para a educação nutricional: uma revisão. Rev Bras Ciênc Farm, v.39, p. 221-225, 2003. 
GOMES, A.L.C. ET al. Orientaçãoalimentar@PRINUTHA: uma ferramenta para a promoção de práticas alimentares saudáveis. Revista Nutrição Brasil, v. 4, n.4, p.188-192, set/out 2005.

HOLLER, H. A review of the American Medical Association's guidelines for medial and health information sites on the internet. J Am Diet Assoc, v. 100, n. 9, p. 1003, 2000.

LÉVY, P. O que é virtual? São Paulo: Editora 34, 2003.

Cibercultura. São Paulo: Ed.34, 1999.

LOPES, I.L. Novos paradigmas para avaliação da qualidade da informação em saúde recuperada na Web Ci. Inf., Brasília, v. 33, n. 1, p. 81-90, jan./abril 2004.

MELO, L.E.V. Gestão do Conhecimento: conceitos e aplicaçōes. São Paulo: Érica, 2003.

MONTEIRO, C.A.; CASTRO, I.R.R. Por que é necessário regulamentar a publicidade de alimentos. Cienc. Cult. São Paulo, v. 61, n. 4, p.56-59, 2009. Disponível em http:// cienciaecultura.bvs.br/pdf/cic/v61n4/20.pdf Acesso em: 11 set 2011.

OENEMA, A.; BRUG, J.; LECHNER, L. Web-based tailored nutrition education: results of a randomized controlled trial. Health Educ Res, v. 16, p. 647-660, 2001.

OKADA, A. Biblioteca virtual iconográfica com Software Nestor Web Cartographer. In: ENCONTRO NACIONAL DE PESQUISA EM CIÊNCIA DA INFORMAÇÃO, ENANCIB 2003., 5. Belo Horizonte, Brasil. 2003. Disponível em http://people.kmi.open. ac.uk/ale/papers/a05enancib2003.pdf Acesso em: 11 set 2011.

OKADA, A. Cartografia Cognitiva: mapeando conhecimento e organizando rede de informação na Internet. In: KNOWLEDGE MANAGEMENT MEETING, KM BRASIL 2003., 2. São Paulo, Brasil. 2003a. http://people.kmi.open.ac.uk/ale/papers/ a03kmbrasil2003.pdf Acesso em: 11 set 2011.

OKADA, A. WebMaps. Um guia para construção do conhecimento em ambientes virtuais de aprendizagem, 2002. Disponível em: http://www.nuted.ufrgs.br/oficinas/criacao/ webmaps.pdf Acesso em: 11 set 2011.

ORGANIZACIÓN MUNDIAL DE LA SALUD. Cinquenta-siete asamblea mundial de la salud. Estrategia mundial sobre régimen alimentario, actividade física y salud. Ginebra, WHO, 2004.

PAINTER, J. Virtual estimation: internet program helps users determine nutrient intake and needs. J Am Diet Assoc, v.100, n. 9, p. 1002, 2000.

PITANGA, F.J; LESSA, I. Prevalência e fatores associados ao sedentarismo no lazer em adultos. Cadernos de Saúde Pública, v. 21, n. 3, p. 870-877, 2005.

SILVA, D.O. et al. Concepções de profissionais de saúde da atenção básica sobre a alimentação saudável no Distrito Federal, Brasil. Cadernos de Saúde Pública, v. 18, n. 5, p.1367-1377, 2002. 
SOARES, M.C. Textos de la CiberSociedad, 2004 Disponível em: http://encipecom. metodista.br/mediawiki/images/3/30/INTERNET_E_SAUDE_-_Murilo.pdf Acesso em: 11 set 2011 .

WORLD HEALTH ORGANIZATION. Diet, nutrition and prevention of chronic diseases: report of a joint WHO/FAO expert consultation. Geneva: WHO, 2003. (Who Technical Report Series, 916).

- Obesity: preventig and managing the global epidemic. Report of a WHO consultation. Geneva: WHO, 1998.

\section{Agradecimentos}

Ao CNPq, que financiou o projeto através do Edital MCT/CNPq/MS-SCTIEDECIT/SAS-DAB 51/2005. Aos profissionais das ONGs que responderam às entrevistas, expressando seus interesses pelo tema. Às nutricionistas que colaboraram com entusiasmo com o projeto, participando das oficinas e realizando as buscas na internet.

\section{Notas}

${ }^{1}$ MUD - Multi-User-Dungeons, jogos de aventura com vários participantes (LEVY, 1999, p.162). MOO significa MUDs Object Oriented, uma variante dos MUDs originais" (LEVY, 1999, p.162).

${ }^{2}$ Disponível em http://www.uwf.com

${ }^{3}$ Disponível em http://www.gate.cnrs.fr/ zeiliger/nestor/nestor.htm

${ }^{4}$ Disponível em http://www.abong.org.br/

${ }^{5}$ Disponível em http://www.net-escola.ufba.br/

${ }^{6}$ Este artigo apresenta resultados de pesquisa coordenada por Rangel-S, M. L., desenvolvida com o apoio financeiro do $\mathrm{CNPq}$, mediante edital. A autora principal concebeu o artigo, as coautoras participaram igualmente em todas as etapas da elaboração do artigo. 


\section{Abstract}

Healthy Nutrition: access to information via navigation maps on the internet

We present and discuss the results of a survey that aimed of develop an information and communication technology in the web in order to promote healthy nutrition, by facilitating access to information on the internet. We sought through interviews, knowing the concepts and identifying demands and needs for information and knowledge on the subject, among NGO's working with health. Besides, mapping information and knowledge about the healthy eating on the web at national sites. From the results, concept maps were prepared, placed in dialogue, mediated by researchers with the knowledge of experts. The paper also describes the methodology used to build navigation maps oriented by concept maps and discusses the challenges of management and access to health information and knowledge on the internet. We highlight the potential to shift the model of supply information for the shared construction of knowledge mediated by information and communication technologies.

> Key words: healthy nutrition; internet and health; communication technology. 